\title{
High-Volume Hemofiltration in Sepsis
}

\author{
Theoretical Basis and Practical Application
}

\author{
Karl Reiter ${ }^{a}$ Vincent D'Intinia Valeria Bordonia Ian Baldwin ${ }^{b}$ \\ Rinaldo Bellomo ${ }^{\text {b }}$ Ciro Tettac Alessandra Brendolanc Claudio Ronco ${ }^{c}$ \\ aPediatric Intensive Care Unit, University Children's Hospital, Munich, Germany; b Department of Intensive Care, \\ Austin and Repatriation Medical Center, Melbourne, Australia; 'Department of Nephrology, St. Bortolo Hospital, \\ Vicenza, Italy
}

\section{Introduction}

Continuous renal replacement therapy (CRRT) in the ICU is a common treatment in acute renal failure (ARF). CRRT is mainly conceived as merely supportive and as a replacement of the lost kidney function. On the other hand, evidence accumulating over the last years demonstrates that many soluble mediators of the systemic inflammatory (and anti-inflammatory) response syndrome can be removed by CRRT. This has led to the suggestion that CRRT could play a major role in sepsis therapy as immunomodulatory treatment and not only as a blood purification technique. In this perspective, whereas animals studies yielded encouraging results, early clinical trials only showed minor clinical benefits, mainly dealing with hemodynamic improvements. The question of treatment dose has appropriately been raised which still has to be defined and it represents a matter of controversy. A large-scale clinical trial has clarified issues on treatment dose in ARF, but a sufficiently powered study on hemofiltration dose in sepsis is still lacking.

In this article we will review the rationale for application of CRRT in treatment of the septic syndrome with specific focus on the use of high ultrafiltration rates (i.e. high-volume hemofiltration: HVHF). We will integrate the discussion into the most recent hypothesis proposed to explain some of the clinical results obtained with high efficiency non-selective removal of mediators of sepsis.
Further, we will describe the necessary technical requirements for HVHF and the most recent machine development concurring with these.

\section{The Rationale of CRRT in Sepsis}

The sepsis syndrome has been described as a systemic malignant inflammation, where the circulation is invaded by enormous amounts of pro-inflammatory mediators produced by activated mononuclear cells. In fact, sepsis is associated with an overwhelming, systemic overflow of both pro- and anti-inflammatory mediators; this leads to altered immune cellular responsiveness, generalized endothelial damage and multiple organ failure derived from a complete disruption of the 'immunological homeostasis' $[1,2]$.

The characteristics of the mediator network are of fundamental relevance in order to allow selection of the most rational and effective treatment approach. The network is redundant and synergistic; it acts like a cascade modulated by multiple positive and negative feedback loops. A vast array of humoral mediators involved have been identified exerting pro-inflammatory effects; on the other hand, a seemingly equally broad spectrum of molecules with opposite function has been demonstrated to emerge in the time course of the septic syndrome. Both pro- and anti-inflammatory mediators, while designed to mainly

\begin{tabular}{ll}
\hline KARGER & ( ) 2002 S. Karger AG, Basel \\
Fax +4161306 1234 & 0028-2766/02/0922-0251\$18.50/0 \\
$\begin{array}{l}\text { E-Mail karger@karger.ch } \\
\text { www.karger.com }\end{array}$ & $\begin{array}{l}\text { Accessible online at: } \\
\text { www.karger.com/journals/nef }\end{array}$
\end{tabular}

\footnotetext{
C. Ronco, MD

Department of Nephrology

St. Bortolo Hospital

I-36100 Vicenza (Italy)
} 


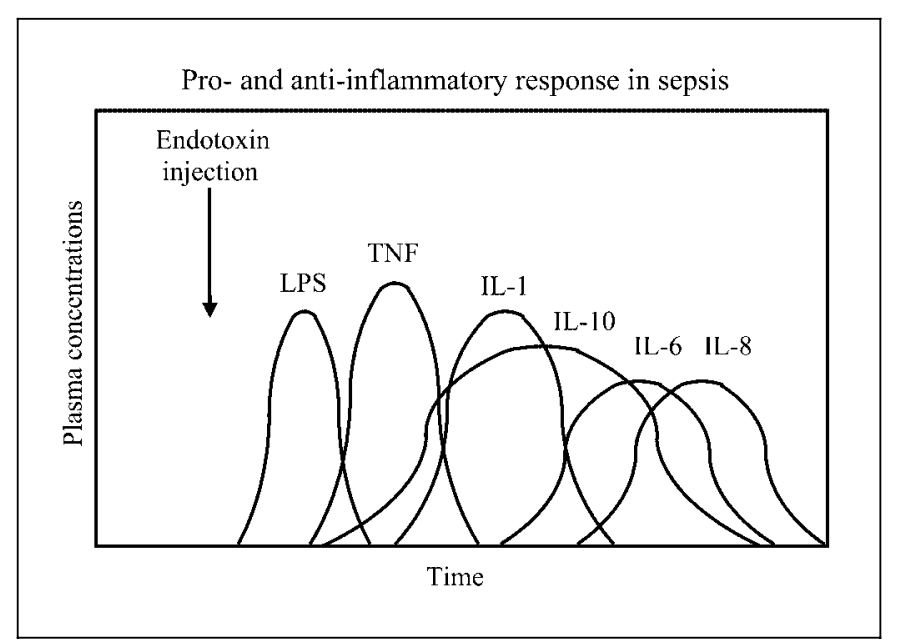

Fig. 1. The sequential appearance of various cytokines in sepsis.

act in an autocrine and/or paracrine mode, are spilling over into the circulation during sepsis and display disastrous systemic effects. In some circumstances, depending on which additional stimuli are present, the same mediator can exert alternatively pro- or anti-inflammatory action. Apart from inciting substances (e.g. endotoxin, products of cell injury) and very early mediators of the septic process (e.g. complement factors, F XIIa) chemokines and cytokines have a central role in the propagation of the inflammatory process including regulatory effects on immune cells. In fact, mortality in sepsis is correlated with persistently elevated levels of pro-inflammatory cytokines $[3,4]$ and in a parallel way, persisting immune cellular hypo-responsiveness associated with high levels of antiinflammatory cytokines $[5,6]$. This has been similarly observed early in the sequence of effects induced by endotoxin injection in animal models (fig. 1) [7].

\section{The Peak Concentration Hypothesis}

The concept of blocking one mediator has not led to measurable outcome improvement in patients with sepsis [8]. Possibly more rigidly defined subgroups would gain profit by TNF-antagonizing treatments [9]. On the other hand, it has been shown that antagonizing a cytokine could lead to deleterious consequences encompassing substantially higher mortality [10]. A low-level TNF response seems to be necessary for the host defense to infection [11, 12] as well as high levels seemingly need to be modulated by an anti-inflammatory feedback; in sepsis, however, failed regulation may cause an excess of anti-inflammato-

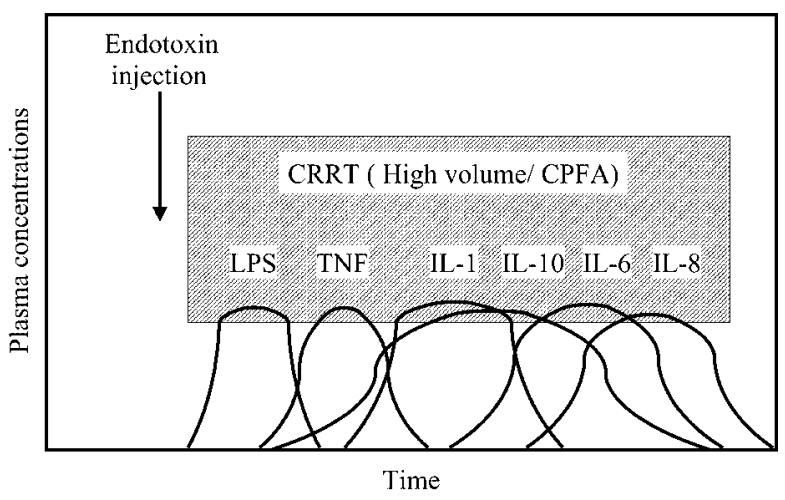

Fig. 2. The peak concentration hypothesis: the sequential appearance of various cytokines in sepsis is schematically depicted. By CRRT, peak plasma cytokine levels could be unselectively reduced bringing the organism at a less severe degree of immunological derangement. Lower levels of pro- and anti-inflammatory mediators could allow the restoration of immuno-homeostasis.

ry response which generates monocyte downregulation and exposes to further infections. Both these processes (inflammation and anti-inflammation) are designed to act in response to specific stimuli in a well-balanced fashion defined as immuno-homeostasis. The excess of one over the other may produce a deleterious effect either leading to systemic inflammation or immune-cell hyporesponsiveness. In the septic syndrome, it seems that these processes are both exaggerated in the time course of the disease and may put the patient alternatively at risk for endothelial dysfunction and shock, or overwhelming infections.

Furthermore, the time point in the septic process of therapeutic intervention seems to be crucial. As the network acts like a cascade early intervention would seem most beneficial. On the other hand, sepsis does not fit a one-hit model but shows complex and varying time courses in mediator levels. Neither single-mediator-directed nor one-time interventions therefore seem appropriate.

One of the major criticisms attributed to continuous blood purification treatments in sepsis - its lack of specificity - could turn out to be a major strength. Unspecific removal of soluble mediators - be they pro- or antiinflammatory - without completely eliminating their effect may be the most logical and adequate approach to a complex and long-running process like sepsis. The concept of cutting peaks of soluble mediators, e.g. through continuous hemofiltration (fig. 2), is a paradigm called by us 'the peak concentration hypothesis' [13]. 


\section{Ultrafiltration Dose and Outcome}

Numerous in vitro as well as animal and human studies [reviewed in 14] have shown that synthetic filters in common use in hemofiltration can extract nearly every substance involved in sepsis to a certain degree. Prominent examples are complement factors $[15,16]$, TNF, IL-1, IL-6 [17-19], IL-8 [20] and PAF [21].

Regarding plasma cytokine levels the decreases appeared nevertheless of minor degree. Other studies could not show any influence on cytokine plasma levels by CRRT [22, 23].

On the other hand significant clinical benefits in terms of hemodynamic improvement have been achieved even without measurable decreases in cytokine plasma levels [24].

Obviously the removal of substances different to the measured cytokines was responsible for the achieved effect. In alternative, bioactive substances including some of the measured cytokines were removed causing the observed beneficial effect. When the response to sepsis is viewed in a network perspective, absolute values would be less relevant than relative ones within an array of interdependent mediators as even small decreases could induce major balance changes. This makes measurement of cytokine plasma levels debatable whilst more local or tissue levels should be measured. These issues are extremely controversial and do not permit a definitive solution in favour or against the use of CRRT as a therapy of sepsis. In this context a further step in clarifying the immunological impact of CRRT has been taken by measuring a more downstream event integrating several cytokine influences: the monocyte responsiveness $[25,26]$.

In spite of some encouraging results as mentioned, the extent of achievable clinical benefit with conventional CRRT (using conventional filters and flow rates) in sepsis has generally been disappointing. Consequently it was sought to improve the efficiency of the methodology regarding removal of soluble mediators of sepsis by increasing the amount of plasma water exchange, i.e. increasing ultrafiltration rates.

Animal studies provided much support of this concept. Starting in the early nineties several studies using different septic animal models examined the effect of high ultrafiltration rates (up to $300 \mathrm{ml} / \mathrm{kg} / \mathrm{h}$ ) on physiological parameters and outcome.

In a landmark study, a porcine model of septic shock induced by endotoxin infusion was investigated [27]. The animals developed profound arterial hypotension and a decrease in cardiac output, stroke volume and right ven- tricular stroke work index. By HVHF at 6 liters/h right ventricular function, blood pressure and cardiac output showed a remarkable improvement compared to control and sham-filtered animals [27, 28]. The same group extended their findings in the same model by intravenously administering ultrafiltrate of endotoxin-infused animals into healthy animals. These developed a hemodynamic picture similar to septic shock whereas animals infused with ultrafiltrate of healthy animals showed a moderate blood pressure rise [29].

In a further study by the same group a bowel ischemiareperfusion model in pigs was investigated. HVHF started before clamping of the superior mesenteric artery significantly diminished bowel damage and prevented hemodynamic deterioration [30].

These classic studies established that a convectionbased treatment can remove substances with hemodynamic effects resembling septic shock, when sufficiently high ultrafiltration rates are applied.

Several studies confirmed and refined these results. In three of them [31-33] the correlation of survival with ultrafiltration rate was specifically examined. A direct correlation could be demonstrated. Significant improvements in cardiac function, systemic and pulmonary vascular resistance and hepatic perfusion [31] were found. Another study in lambs showed significant improvements in lung function [34]. Only a minority of studies identified reduced mediator plasma levels $[33,35]$.

A very recent study in pigs made septic by induced pancreatitis compared low-volume CVVH with HVHF of $100 \mathrm{ml} / \mathrm{kg} / \mathrm{h}$. In the same study the influence of frequent filter changes on survival, changes in TNF levels as well as monocyte and PMNL function was analyzed [33]. Early filter change allows to delineate the effect of cytokine removal by adsorption on the filter since membrane capacity saturates after a few hours. By changing filters, adsorption is continued to a certain extent.

In this model a hyperdynamic septic picture is induced through an intervention which approximates underlying conditions encountered in human sepsis. Additionally the intervention started late to simulate real clinical conditions. Hemofiltration was commenced when the animals developed the clinical picture of hyperdynamic septic shock. HVHF was superior in all mentioned endpoints and, importantly, increasing ultrafiltration had more effect than frequency of filter change [33].

Of major influence concerning human sepsis studies has been the finding that ultrafiltration dose is correlated to outcome in critically ill patients with ARF. In a large randomized, controlled study including 425 patients, an 
Fig. 3. Survival rates observed in patients treated with different hemofiltration dose. While the effects is evident in the overall population from group 1 to group 2 and no further effect is observed on group 3, when patients are stratified for sepsis, a significant effect of higher doses of treatment is observed in group 3.

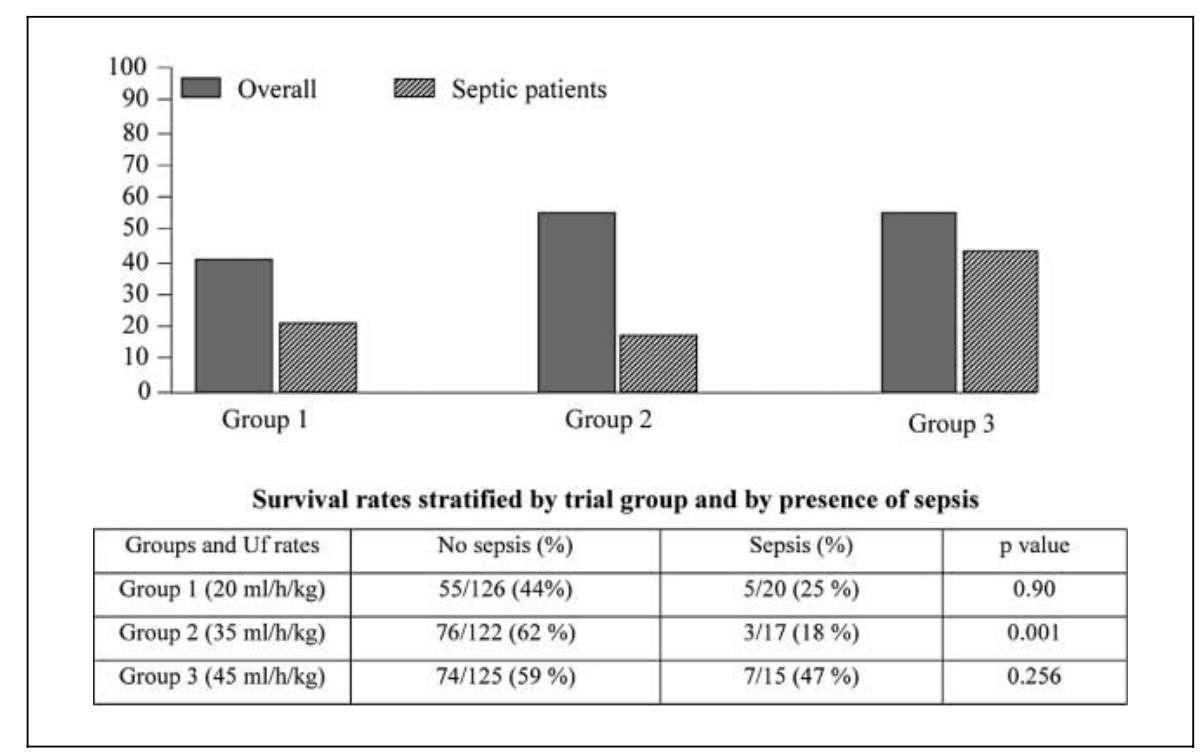

ultrafiltration dose of $35 \mathrm{ml} / \mathrm{kg} / \mathrm{h}$ increased survival rate from 41 to $57 \%$ compared to a dose of $20 \mathrm{ml} / \mathrm{kg} / \mathrm{h}$ [36].

Eleven to $14 \%$ (per randomization group) of the patients had sepsis. In these subgroups there was a trend of direct correlation of treatment dose with survival even above $35 \mathrm{ml} / \mathrm{kg} / \mathrm{h}$ in contrast to the whole group where a survival plateau was reached (fig. 3).

This lends support to the concept of a 'sepsis dose' of hemofiltration in septic patients contrasting to a 'renal dose' in critically ill patients without systemic inflammation, the former being probably distinctly higher (without proven upper limit). Of note, there was no increase in adverse effects even with the highest ultrafiltration dose.

Over the last years several human studies examined the clinical effects of high-volume hemofiltration. In 20 children undergoing cardiac surgery, zero-balanced HVHF was administered with UF rates equivalent to 79 liters/h for a 70-kg adult [37]. Endpoints correlating to the cardiopulmonary-bypass-associated delayed inflammatory response were examined. There was a significant reduction in post-operative blood loss, time to extubation and improvement in the arterial-alveolar oxygen gradient.

In a prospective cohort analysis in 306 critically ill patients with varying underlying diseases a mean ultrafiltration rate of 3.8 liters/h was applied [38]. Observed survival rates were significantly higher in the treated population compared to predicted survival by three well-validated scores.

A study in 12 critically ill patients with ARF comparing low-volume CVVH $(1,500 \mathrm{ml} / \mathrm{h})$ with a high-volume technique was performed in a non-randomized, comparative fashion [39]. High-flux bicarbonate dialysis amounting to $4,200 \mathrm{ml} / \mathrm{h}$ was used and the effect on monocyte responsiveness (ex vivo endotoxin-stimulated TNF production) was studied. Both techniques resulted in early improvement but only in the high-volume technique displayed persistent effects. Ultrafiltrate contained monocyte suppressive activity only with high-flux dialysis.

In another trial in 11 septic patients with shock and MODS a randomized cross-over design of 6 vs. 1 liters/h ultrafiltration was applied [40]. The HVHF group displayed significantly greater reduction in vasopressor requirements (fig. 4). Both treatment groups showed a decrease in $\mathrm{C} 3 \mathrm{a}$ and $\mathrm{C} 5 \mathrm{a}$ plasma levels which was significantly greater in the HVHF group.

Impressive clinical results were obtained in an evaluation of short-term HVHF in 20 patients in catecholaminerefractory septic shock [41] comprising a patient cohort with very poor expected survival. A control group was not defined. Only one 4-hour session of HVHF removing 35 liters of ultrafiltrate replaced by bicarbonate-containing fluid was applied as soon as mean blood pressure could not be stabilized above $70 \mathrm{~mm} \mathrm{Hg}$ with dopamine, norepinephrine and epinephrine after appropriate volume resuscitation. HVHF was followed by conventional CVVH. Endpoints were the increase in cardiac index, mixed venous oxygen saturation and arterial $\mathrm{pH}$ and decrease in epinephrine requirements. Eleven patients reached all predefined endpoints and showed impressively good survival ( 9 of 11 ) at 28 days. Nine patients did not reach all endpoints and had a $100 \%$ mortality rate. Apart 


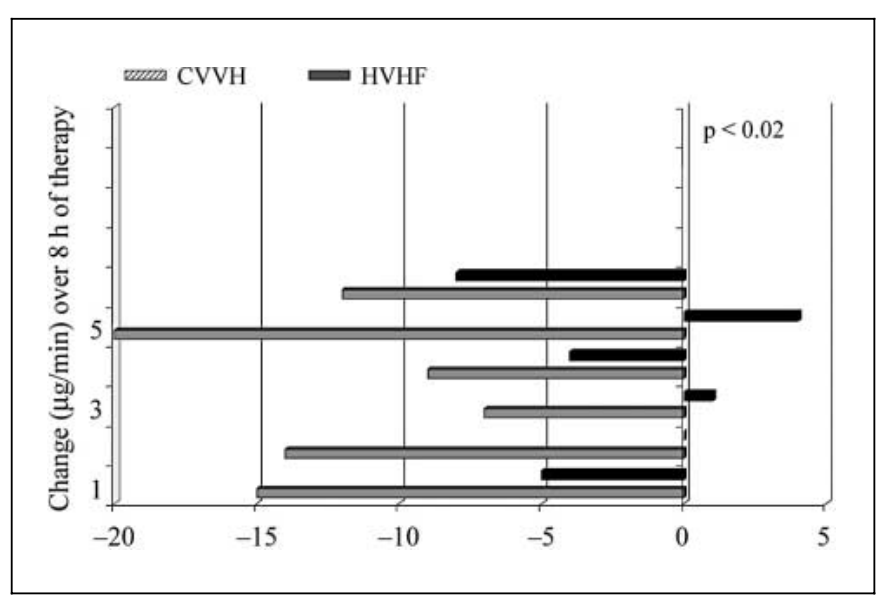

Fig. 4. Significant reduction in norepinephrine requirement is observed in unstable septic patients treated with high-volume hemofiltration. Less evident is the effect of low-volume CVVH.

from responding to HVHF, only time from ICU admission to start of HVHF and body weight were survivalassociated factors in the analysis. Patients with higher body weight did worse possibly because they received a smaller ultrafiltration dose per body weight as speculated by the authors.

These trials still need cautious interpretation with respect to their limited design, but they certainly deliver sound evidence of feasibility and efficacy to set the stage for a large-scale trial on HVHF in sepsis.

\section{Unsolved Issues}

Ultrafiltration is associated with loss of a vast array of water-soluble substances. Not all of these losses are desired and many have not been characterized quantitatively [42] or even qualitatively. HVHF constitutes a major intervention in acid-base balance as much strong ions and up to now poorly defined small to middle molecular acids (and bases) of intermediate metabolism are filtered.

Furthermore, lactate replacement fluid leads to hyperlactatemia which possibly can be tolerated well even in septic shock [43], but not in all patient groups [44, 45]. Bicarbonate replacement would appear physiologic but is very expensive and not available in many parts of the world.

Losses of hormones, vitamins, molecules of intermediate metabolism and amino acids in HVHF have not been studied up to now. As CRRT can be regarded as a powerful metabolic intervention (constituting a contin- uous plasma water exchange), its intensification by using HVHF may encompass undefined dangers (by loss of specific substances, by high lactate loads). On the other hand, it possibly opens a therapeutic avenue to administer substances with specific metabolic activity without volume restriction (e.g. inosine [46], pyruvate [47]).

Another issue involved the modification of thermal energy balance especially when high volume of fluid is exchanged. Specific studies have not been carried out, but an increasing consensus exists on the need for a fluid warmer in the newly designed machines.

\section{Methodological Aspects of HVHF}

Major methodological details in using a technique which deserves a fluid exchange rate of 6 liters/h and more (possibly up to 10 liters $/ \mathrm{h}$ what would equal about $140 \mathrm{ml} / \mathrm{kg}$ in a $70-\mathrm{kg}$ adult) have to be considered. To avoid excessive hemoconcentration within the filter with consecutive clotting problems high blood flows in the range of 400$500 \mathrm{ml} / \mathrm{min}$ have to be applied. For the same reason at least part of the replacement fluid has to be administered in a predilution mode. This may reduce middle molecule clearance proportionally by the dilutional effect at filter entry [55].

Certainly high volumes increase risks of technical problems (catheter problems, disconnection, dosing errors). Catheters have to be large to tolerate blood flows at least above $300 \mathrm{ml} / \mathrm{min}$. High blood flows must be maintained at all times and in variable patient positions with minimal recirculation.

Consequently, the technique needs a high level of supervision by experienced personnel exclusively devoted to the treated patient. Most practical in this respect seems to be an intermittent technique with HVHF over 4-8 h during daytime embedded in conventional $\mathrm{CVVH}$ for the rest of the day. Furthermore, high amounts of replacement fluids are needed which may reach financial limits. Systems designed for in-line preparation of fluids by cascade filtration may have to be considered.

Obviously the hemofiltration machine is vital for the safe performance of HVHF. First of all machines need to be capable of administering volumes in this range including warming capacity. Further safety regards are appropriate pressure monitoring, exactness in applying high volumes and calculating balances. Certainly a friendly user interface and the easiness of use is a must (fig. 5).

The Aquarius Haemofiltration machine (ELS, Germany) has been developed specifically to reach the above-mentioned goals and serves as a representative of the latest generation of machines in the field. In this machine, HVHF can be performed in addition to all other types of blood purification therapies considered for use in the ICU.

Blood flows required for effective HVHF in the range of 300$450 \mathrm{ml} / \mathrm{min}$ can be programmed. Ultrafiltration rate in the range of 6 liters/h (requiring replacement fluid infusion rates of about $100 \mathrm{ml} / \mathrm{min}$ ) can be prescribed as well.

The Aquarius machine delivers pump flow rates up to $450 \mathrm{ml} /$ min for blood, up to 10 liters/h for pre- or postdilution replacement and up to $2,000 \mathrm{ml} / \mathrm{h}$ for additional fluid removal.

Volume accuracy as well as sensitive, fast-response pressure monitoring is of utmost importance in these high ranges. 


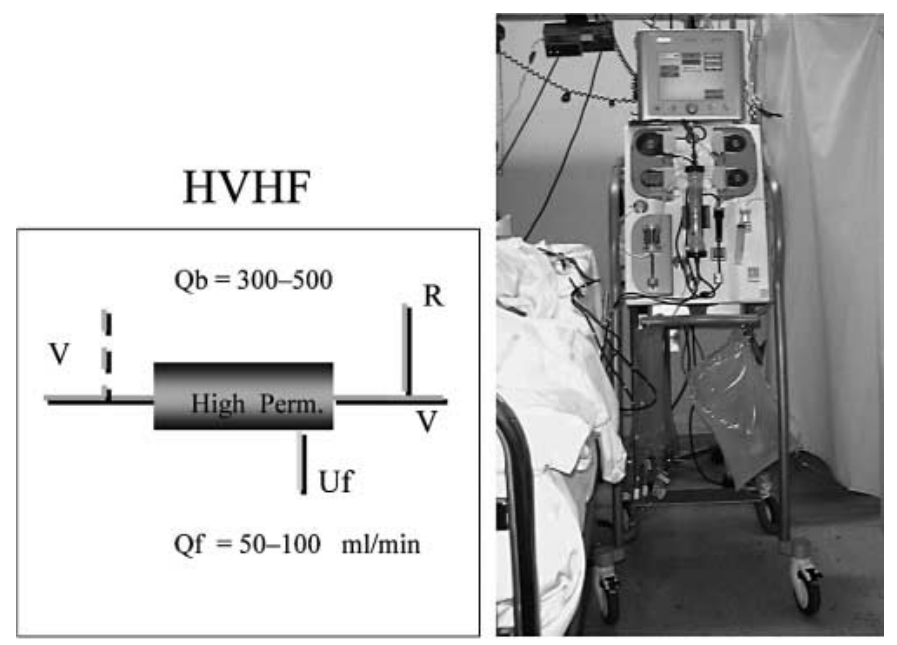

Fig. 5. High-volume hemofiltration performed either in pre or postdilution modes (machine: Aquarius from Edwards Life Sciences $\mathrm{GmbH}$, Unterschleissheim, Germany).

This is properly realized with scales ensuring substitution and filtrate volume accuracy with $0.1 \%$ precision. Pump accuracy reaches $5 \%$. Only a 50 -gram deviation of the target value is permitted before alarming will be activated. Precision within this range is obligatory for HVHF.

Replacement fluid can be administered in a pre- and post-dilution mode and concurrently. Pressure monitoring is installed in the access and return line as well as in a prefilter position and in the ultrafiltrate compartment. Sensor accuracy amounts to $\pm 5 \mathrm{~mm} \mathrm{Hg}$. The pressure sensors operate without blood-air interface. Air embolism is prevented by an ultrasonic air detector which controls a line clamp. Effective heating capacity is essential when high volumes are processed. Otherwise major energy losses and possibly severe hypothermia could be induced in the patient. For this purpose the machine uses a coil-tubing design which ensures heating up to $39^{\circ} \mathrm{C}$ up to 6 liters/h fluid turnover. HVHF is a high-risk procedure regarding immediate consequences of technical or user errors. In order to minimize their probability of occurrence user-friendly properties are of high priority. This need is served by the concept of a one-button machine. A single selector knob guides all functions supported by a self-explanatory screen.

\section{Other Approaches to High Efficiency Blood Purification in Sepsis}

Cytokines and other immunomodulating substances have generally molecular weights in the range from 5 to $50 \mathrm{kD}$. They may be eliminated by diffusion, convection or adsorption depending on material and the rather variable cut-off of highly permeable membranes (from 30 to $40 \mathrm{kD}$ ) [17]. As adsorptive processes easily saturate and
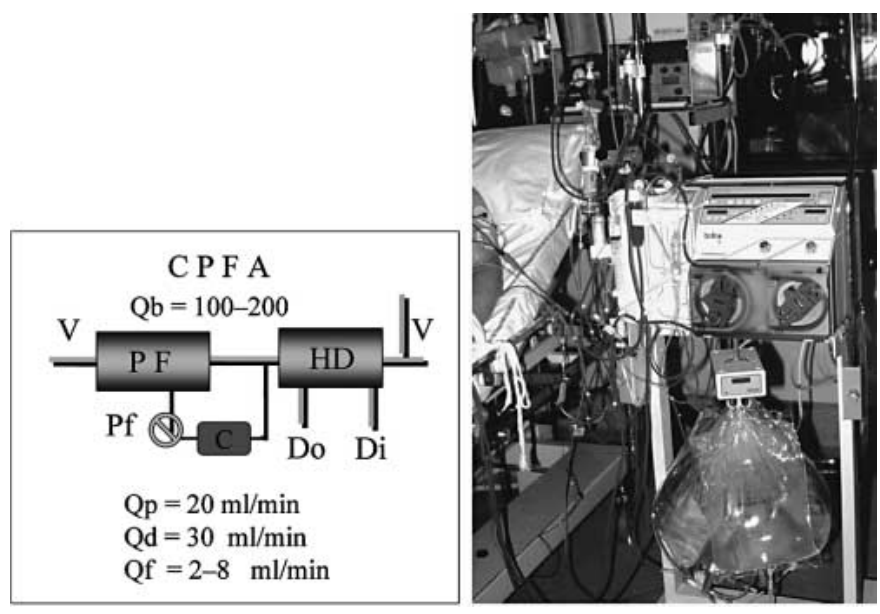

Fig. 6. Coupled plasma filtration with adsorption. Plasma filtered in a plasma filtration unit is circulated through an adsorbent cartridge and then returned to the main stream. Reconstituted blood is then dialyzed (machine: Multimat B from Bellco s.p.a., Mirandola, Italy).

are therefore transient, the effect of CRRT on sepsis could be limited because of a low convective clearance of many mediators.

Therefore other approaches to achieve higher mediator clearance in sepsis have been sought. Apart from increasing ultrafiltration rates, higher removal rates of middle molecular weight molecules could be achieved by enlarging pore size of membranes. Animal data $[49,50]$ as well as preliminary clinical data [51] demonstrate feasibility and probable superior removal rates of select cytokines using larger cut-off membranes.

A study in 30 patients with severe sepsis using continuous plasmafiltration for $34 \mathrm{~h}$ [52] found attenuation of the acute-phase response and a trend towards clinical benefit although not significant (fewer failing organs). A further refining has been achieved with plasma filtration coupled with adsorption and followed by dialysis or filtration (fig. 6) [53]. This would allow effective removal of mediators in the borderline zone of filtration by hemofilters (40-60 kD) without the need of exogenous plasma replacement. Furthermore higher plasma clearance rates could be achieved. An animal study [54] and a first clinical trial reported beneficial effects on hemodynamic and immune cell function $[26,55]$.

Conclusions on efficiency would be premature to draw. Taken the available data together more studies are required to see a major advantage in laboratory and clinical endpoints with plasma filtration compared to ultrafiltration techniques. 
Certainly larger pore size membranes and plasma filtration combined with sorbent techniques enlarge the therapeutic armamentarium significantly. They constitute a promising adjunctive modality easily to be used in combination with hemofiltration.

\section{Concluding Remarks}

A vast array of mostly water-soluble mediators play a strategic role in the septic syndrome. Compared to eliminating or completely antagonizing single mediators, therapeutic intervention by nonselective removal of pro- and anti-inflammatory mediators seems a rational and possibly superior concept. A further advantage seems to be constituted by a continuously acting therapy as in the case of continuous renal replacement therapies. Hereby, sequentially appearing peaks of systemic mediator overflow could be curbed as well as persistently high plasma levels reduced. This process is proposed as the underlying biological rationale for a series of innovative therapies in sepsis. The whole story of antagonizing pro- and anti-inflam- matory processes by reducing the relative excess of active substances undergoes the term of 'peak concentration hypothesis'.

Recent animal and human trials have delivered much support to this concept. It has been conclusively shown that treatment dose in CRRT is a major factor concerning survival in ARF in the critically ill patient. There is accumulating evidence of increased efficacy of high-volume hemofiltration compared to conventional CVVH in terms of laboratory and clinical improvement including survival. Machines to perform HVHF safely are available on the market.

Yet the evidence still is not strong enough to recommend HVHF outside clinical studies taking into account possible adverse effects of the technique. A large-scale clinical trial is urgently needed to resolve the issue.

Other blood purification techniques using large pore membranes or plasma filtration with sorbent perfusion are in the early stages of clinical testing. They are conceptually promising and possibly constitute an important refinement.

\section{References}

1 Pinsky MR: Sepsis: A pro- and anti-inflammatory disequilibrium syndrome. Contrib Nephrol. Basel, Karger, 2001, vol 132, pp 354 366.

2 Adrie C, Pinsky MR: The inflammatory balance in human sepsis. Intens Care Med 2000; 26:364-375.

3 Casey LC, Balk RA, Bone RC: Plasma cytokine and endotoxin levels correlate with survival in patients with the sepsis syndrome. Ann Intern Med 1993;15:771-778.

4 Pinsky MR, Vincent JL, Deviere J, Alegre M, Kahn RJ, Duont E: Serum cytokine levels in human septic shock. Relation to multiple-system organ failure and mortality. Chest 1993; 103:565-575.

5 Adib-Conquy M, Adrie C, Moine $\mathrm{P}$, Ashnoune K, Fitting C, Pinsky MR, Dhainaut JF, Cavaillon JM: NF-kB expression in mononuclear cells of septic patients resembles that observed in LPS tolerance. Am J Respir Crit Care Med 2000;162:1877-1883.

6 van Dissel JT, van Langevelde P, Westendorp RG, Kwappenberg K, Froelich M: Anti-inflammatory cytokine profile and mortality in febrile patients. Lancet 1998;351:950-953.

7 Klosterhalfen B, Horstmann-Jungemann K, Vogel P, Dufhues G, Simon B, Kalff G, Kirkpatrick CJ, Mittermayer C, Heinrich PC: Hemodynamic variables and plasma levels of PGI2, TXA 2 and IL- 6 in a porcine model of recurrent endotoxemia. Circ Shock 1991;35:237-244.
8 Abraham E, Matthay M, Dinarello CA, Vincent JL, Cohen J, Opal SM, Glauser M, Parsons P, Fisher CJ, Repine JE: Concensus Conference definitions for sepsis, septic shock, acute lung injury, and acute respiratory distress syndrome: Time for a reevaluation. Crit Care Med 2000;28:232-235.

9 Abraham E, Glauser MP, Butler T, Garbino J, Gelmont D, Laterre PF, Kudsk K, Bruining HA, Otto C, Tobin E, Zwingelstein C, Lesslauer W, Leighton A: p55 tumor necrosis factor receptor fusion protein in the treatment of patients with severe sepsis and septic shock: A randomized controlled multicenter trial. Ro 45-2081 study group. JAMA 1997;277:15311538.

10 Fisher CJ, Agosti JM, Opal SM: Treatment of septic shock with the tumor necrosis factor receptor: Fc fusion protein. N Engl J Med 1996;334:1697-1702.

11 Echtenacher B, Falk W, Mannel D, Krammer PH: Requirement of endogenous tumour necrosis factor/cachectin for recovery from experimental peritonitis. J Immunol 1990;145: 3762-3766.

12 van der Meer JWM: The effects of recombinant interleukin-1 and recombinant tumor necrosis factor on non-specific resistance to infection. Biotherapy 1988;1:19-25.
13 Ronco C, Ricci Z, Bellomo R: Importance of increased ultrafiltration volume and impact on mortality: Sepsis and cytokine story and the role of continuous veno-venous hemofiltration. Curr Opin Nephrol Hypertens 2001;10:755761.

14 De Vriese AS, Vanholder RC, Pascual M, Lameire NH, Colardyn FA: Can inflammatory cytokines be removed efficiently by continous renal replacement therapies? Intens Care Med 1999;25:903-910.

15 Hoffmann JN, Hartl WH, Deppisch R, Faist E Jochum M, Inthorn D: Hemofiltration in human sepsis: Evidence for elimination of immunomodulatory substances. Kidney Int 1995;48: 1563-1570.

16 Gasche Y, Pascual M, Suter PM, Favre H, Chevrolet JC, Schifferli JA: Complement depletion during haemofiltration with polyacylonitrile membranes. Nephrol Dial Transplant 1996;11:117-119.

17 Kellum JA, Johnson JP, Kramer D, Palevsky P, Brady JJ, Pinsky MR: Diffuse vs. convective therapy: Effects on mediators of inflammation in patients with severe systemic inflammatory response syndrome. Crit Care Med 1998;26: 1995-2000.

18 Goldfarb J, Golper TA: Proinflammatory cytokines and hemofiltration membranes. Am Soc Nephrol 1994;5:228-232. 
19 Braun N, Giolai M, Rosenfeld S, Banzhaff W, Fretschner R, Weinstock C, Erley C, Mueller GA, Warth H, Northoff H, Risler T: Clearance of interleukin-6 during continuous veno-venous hemofiltration in patients with septic shock: A prospective, controlled clinical study (abstract). J Am Soc Nephrol 1993;4:336.

20 Mariano F, Tetta C, Guida GE, Triolo G, Camussi G: Hemofiltration reduces the priming activity on neutrophil chemiluminescence in septic patients. Kidney Int 2001;60:15981605.

21 Ronco C, Tetta C, Lupi A, Galloni E, Bettini MC, Sereni L, Mariano F, DeMartino A, Montrucchio G, Camussi G, LaGreca G: Removal of platelet-activating factor in experimental continuous arteriovenous hemofiltration. Crit Care Med 1995;23:99-107.

22 Sander A, Armbruster W, Sander B, Daul AE Lange R, Peters J: Haemofiltration increases IL-6 clearance in early systemic inflammatory response syndrome but does not alter IL-6 and TNF alpha plasma concentrations. Intens Care Med 1997;23:878-884.

23 Cole L, Bellomo R, Journois D, Davenport P, Tipping $\mathrm{P}$, Ronco C: A phase II randomized controlled trial of continuous hemofiltration in sepsis. Submitted.

24 Heering P, Morgera S, Schmitz FJ, Willers R, Schultheiss HP, Strauer BE, Grabensee B: Cytokine removal and cardiovascular hemodynamics in septic patients with continuous venovenous hemofiltration. Intens Care Med 1997;23:288-296.

25 Munoz C, Carlet J, Fitting C, Misset B, Bleriot JP, Cavaillon JM: Dysregulation of in vitro cytokine production by monocytes during sepsis. J Clin Invest 1991;88:1747-1754.

26 Ronco C, Brendolan A, Lonnemann G, Bellomo R, Piccinni P, Digito A, Dan M, Irone M, LaGreca G, Ingaggiato P, Maggiore U, De Nitti C, Wratten ML, Tetta C: A pilot study on couplet plasma filtration with adsorption in septic shock. Crit Care Med, in press.

27 Grootendorst AF, van Bommel EFH, van der Hoven B, van Leengoed LAM, van Osta ALM: High volume hemofiltration improves hemodynamics of endotoxin-induced shock in the pig. J Crit Care 1992;7:67-75.

28 Grootendorst AF, van Bommel EFH, van der Hoven B, van Leengoed LAM, van Osta ALM High volume hemofiltration improves right ventricular function of endotoxin-induced shock in the pig. Intens Care Med 1992;18: 235-240.

29 Grootendorst AF, van Bommel EF, van Leengoed LA, van Zanten AR, Huipen HJ, Groeneveld AB: Infusion of ultrafiltrate from endotoxemic pigs depresses myocardial performance in normal pigs. J Crit Care 1993;8:161169.

30 Grootendorst $\mathrm{AF}$, van Bommel $\mathrm{EFH}$, van Leengoed LAM, Naburus M, Bouman CSC, Groeneveld ABJ: High volume hemofiltration improves hemodynamics and survival of pigs exposed to gut ischemia and reperfusion. Shock 1994;2:72-78.
31 Lee PA, Matson JR, Pryor RW, Hinshaw LB: Continuous arteriovenous hemofiltration therapy for staphylococcus aureus-induced septicemia in immature swine. Crit Care Med 1993; 21:914-924.

32 Rogiers P, Zhang H, Smail N, Auwels D, Vincent JL: Continuous venovenous hemofiltration improves cardiac performance by mechanisms other than tumor necrosis factor-alpha attenuation during endotoxic shock. Crit Care Med 1999;27:1848-1855.

33 Yekebas EF, Eisenberger CF, Ohnesorge H, Saalmueller A, Elsner HA, Engelhardt M, Gillesen A, Mains J, The M, Strate T, Busch C, Knoefel WT, Bloechle C, Izbicki JR: Attenuation of sepsis-related immunoparalysis by continuous veno-venous hemofiltration in experimental porcine pancreatitis. Crit Care Med 2001;29:1423-1430.

34 Nagashima M, Shin'oka T, Nollert G, ShumTim D, Rader CM, Mayer JE Jr: High-volume continuous hemofiltration during cardiopulmonary bypass attenuates pulmonary dysfunction in neonatal lambs after deep hypothermic circulatory arrest. Circulation 1998;98(suppl 19):II378-384.

35 Bellomo R, Kellum JA, Gandhi CR, Pinsky MR: The effect of intensive plasma water exchange by hemofiltration on hemodynamics and soluble mediators in canine endotoxemia. Am J Respir Crit Care Med 2000;161:1429_ 1436.

36 Ronco C, Bellomo R, Homel P, Brendolan A, Dan M, Piccinni P, LaGreca G: Effects of different doses in continuous veno-venous haemofiltration on outcomes of acute renal failure: A prospective randomised trial. Lancet 2000; 356:26-30.

37 Journois D, Israel Biet D, Pouard P, et al: Highvolume, zero-balanced hemofiltration to reduce delayed inflammatory response to cardiopulmonary bypass in children. Anesthesiology 1996;85:965-976.

38 Oudemans-van Straaten HM, Bosman RJ, van der Spoe JI, Zandstra DF: Outcome of critically ill patients treated with intermittent highvolume haemofiltration: A prospective cohort analysis. Intens Care Med 1999;25:814-821.

39 Lonnemann G, Bechstein M, Linnenweber S, Burg M, Koch KM: Tumor necrosis factoralpha during continuous high-flux hemodialysis in sepsis with acute renal failure. Kidney Int 1999;56(suppl 72):S84-87.

40 Cole L, Bellomo R, Journois D, Davenport P, Baldwin I, Tipping P: High-volume hemofiltration in human septic shock. Intens Care Med 2001;27:978-986.

41 Honore PM, Jamez J, Wauthier M, Lee PA, Dugernier T, Pirenne B, Hique G, Matson JR: Prospective evaluation of short-term, high-volume isovolemic hemofiltration on the hemodynamic course and outcome in patients with intractable circulatory failure resulting from septic shock. Crit Care Med 2000;28:3581-3587.

42 Guth HJ, Zschiesche M, Panzig E, Rudolph PE, Jager B, Kraatz G: Which organic acids does hemofiltrate contain in the presence of acute renal failure? Int J Artif Organs 1999;22: $805-810$.
43 Cole L, Bellomo R, Baldwin I, Hayhoe M, Ronco $\mathrm{C}$ : The impact of lactate-buffered high-volume hemofiltration on acid-base balance. Submitted.

44 Barenbrock M, Hausberg M, Matzkies F, de la Motte S, Schaefer RM: Effects of bicarbonateand lactate-buffered replacement fluids on cardiovascular outcome in CVVH patients. Kidney Int 2000;58:1751-1757.

45 Davenport A, Will EJ, Davison AM: Hyperlactatemia and metabolic acidosis during hemofiltration using lactate-buffered fluids. Nephron 1991;59:461-465.

46 Sims CA, Wattanasirichaigoon S, Menconi MJ, Ajami AM, Fink MP: Ringer's ethyl pyruvate solution ameliorates ischemia/reperfusion-induced intestinal mucosal injury in rats. Crit Care Med 2001;29:1513-1518.

47 Soriano FG, Liaudet L, Marton A, Hasko G, Lorigados BC, Deitch EA, Szabo C: Inosine improves gut permeability and vascular reactivity in endotoxic shock. Crit Care Med 2001; 29:703-708.

48 Bellomo R, Baldwin I, Cole L, Ronco C: Preliminary experience with high-volume hemofiltration in human septic shock. Kidney Int 1998;53(suppl 66):182-185.

49 Lee PA, Weger G, Pryor RW, Matson JR: Effects of filter pore size on efficacy of continuous arteriovenous hemofiltration therapy for Staphylococcus aureus-induced septicemia in immature swine. Crit Care Med 1998;26:730 737.

50 Kline JA, Gordon BE, Williams C, Blumenthal S, Watts JA, Diaz-Buxo J: Large-pore hemodialysis in acute endotoxin shock. Crit Care Med 1999;27:588-596.

51 Morgera S, Buder W, Lehmann C, Ziemer S, Haase M, Rocktaeschel J, Beck W, Buck R, Goehl H, Kox WJ, Neumayer HH: High cut off membrane haemofiltration in septic patients with multiorgan failure: A preliminary report (abstract). Blood Purif 2000; 18:61.

52 Reeves JH, Butt WW, Shann F, Layton JE, Stewart A, Waring PM, Presneill JJ: Plasmafiltration in Sepsis Study Group: Continuous plasma filtration in sepsis syndrome. Crit Care Med 1999;27:2096-2104

53 Tetta C, Cavaillon JM, Schulze M, Ronco C, Ghezzi PM, Camussi G, Serra AM, Curti F, Lonnemann G: Removal of cytokines and activated complement components in an experimental model of continuous plasma filtration coupled with sorbent adsorption. Nephrol Dial Transplant 1998;13:1458-1464.

54 Tetta C, Gianotti L, Cavaillon JM, Wratten ML, Fini M, Braga M, Bisagni P, Giavaresi G, Bolzani R, Giardino R: Coupled plasma filtration-adsorption in a rabbit model of endotoxic shock. Crit Care Med 2000;28:1526-1533.

55 Brendolan A, Bellomo R, Tetta C, Piccinni P, Digito A, Wratten ML, Dan M, Irone M, LaGreca G, Ingaggiato P, Ronco C: Coupled plasma filtration adsorption in the treatment of septic shock. Contrib Nephrol 2001;132:383390.

Reiter/D'Intini/Bordoni/Baldwin/Bellomo/ Tetta/Brendolan/Ronco 